\title{
Ambulatory Management of Worsening Heart Failure: Current Strategies and Future Directions
}

\author{
Alison L Wand, ${ }^{1}$ Stuart D Russell ${ }^{2}$ and Nisha A Gilotra ${ }^{1}$ \\ 1. Division of Cardiology, Department of Medicine, Johns Hopkins University School of Medicine, Baltimore, MD, USA; 2. Division of Cardiology, \\ Department of Medicine, Duke University School of Medicine, Durham, NC, USA
}

DOI: https://doi.org/10.17925/HI.2021.15.1.49

$\mathrm{H}$ eart failure (HF) is a highly prevalent and morbid disease in the USA. The chronic, progressive course of HF is defined by periodic exacerbations of symptoms, described as 'worsening heart failure' (WHF). Previously, episodes of WHF have required hospitalization for intravenous diuretics; however, recent innovations in care delivery models for patients with HF have allowed a transition from the acute care setting to the ambulatory setting. The development of remote monitoring strategies, including device-based algorithms and implantable haemodynamic monitoring systems, has facilitated more advanced surveillance of patients, aiming to prevent the clinical deterioration that leads to hospitalization. Additionally, the establishment of multidisciplinary HF clinics has provided the setting and resources for the outpatient treatment of WHF, specifically the administration of intravenous diuretics. Here we review the current state of ambulatory HF management, including mechanisms for patient monitoring and treatment, and outline future opportunities for outpatient management of this patient population.

\section{Keywords}

Heart failure, worsening heart failure, ambulatory treatment, outpatient treatment, remote monitoring, telemonitoring, intravenous diuretics, subcutaneous diuretics

Disclosures: Alison L Wand has no financial or non-financial relationships or activities to declare in relation to this article. Stuart D Russell is an unpaid advisor to scPharmaceuticals, Inc. Nisha A Gilotra has served as an advisor and visiting speaker for scPharmaceuticals, Inc., and has received research funding from Intra-Cellular Therapies, Inc.

Review Process: Double-blind peer review.

Compliance with Ethics: This study involves a review of the literature and did not involve any studies with human or animal subjects performed by any of the authors.

Authorship: The named authors meet the International Committee of Medical Journal Editors (ICMJE) criteria for authorship of this manuscript, take responsibility for the integrity of the work as a whole, and have given final approval for the version to be published.

Access: This article is freely accessible at touchCARDIO.com (C) Touch Medical Media 2021.

Received: 20 January 2021

Accepted: 16 February 2021

Published online: 7 June 2021

Citation: Heart International. 2021;15(1):49-53

Corresponding author: Nisha A Gilotra, Division of Cardiology, Department of Medicine,

Johns Hopkins University School of Medicine,

600 N. Wolfe Street, Carnegie Suite 568,

Baltimore, MD 21287, USA.

E: naggarw2@ihmi.edu

Support: No funding was received for

the publication of this article.
Heart failure (HF) is a highly prevalent and morbid disease in the USA, imposing a significant burden on patients, hospitals and the health system. The prevalence of HF continues to increase, with over 650,000 new HF cases diagnosed annually. ${ }^{1}$ There are over 6.2 million people with HF in the USA, ${ }^{2}$ with an expected increase to 8 million by $2030 .{ }^{3}$ Despite recent additions to the pharmacologic armamentarium available to treat $\mathrm{HF}$, symptomatic $\mathrm{HF}$ remains challenging to manage, with poor outcomes and reduced quality of life for patients and caregivers. ${ }^{4-8} \mathrm{HF}$ is a chronic and progressive disease, characterized by acute exacerbations often necessitating hospitalization. The result is over 1 million HF hospitalizations costing $\$ 30$ billion annually, with costs expected to double in the next decade. ${ }^{910}$ Re-admissions are common, with up to $25 \%$ of patients re-admitted within 30 days post-discharge, and $50 \%$ of patients re-admitted within 6 months..$^{10}$ These re-admissions are particularly costly in the context of health policies, which penalize hospitals with higher-than-predicted re-admission rates. ${ }^{11}$

Strategies that promote improved transition of care from inpatient to ambulatory settings may help decrease the economic toll of HF on the healthcare system, while alleviating patient burden. ${ }^{12}$ Potential benefits include maximizing patient time at home, preventing delays in care associated with emergency department visits and avoiding potential complications of hospitalizations (Table 1). ${ }^{13}$ Here we review the current state of outpatient HF management, including defining

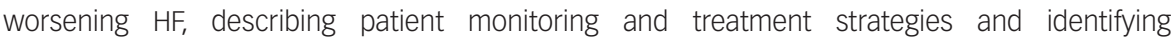
opportunities for ambulatory HF care delivery. Further, we outline future directions for the ambulatory management of this expanding patient population.

\section{Defining worsening heart failure}

The progressive course of $\mathrm{HF}$ is characterized by a slow clinical decline over years with episodic exacerbations, described as 'worsening heart failure' (WHF). ${ }^{14-16} \mathrm{HF}$ symptoms - including lower extremity oedema, dyspnoea at rest and with exertion, orthopnoea, paroxysmal nocturnal dyspnoea and abdominal distention - are largely attributable to congestion. ${ }^{17}$ Symptoms of congestion are associated with reduced quality of life in HF and are frequent reasons patients present for acute care.17-19 Historically, WHF has required hospitalization for treatment with intravenous (IV) loop diuretics. ${ }^{20}$ WHF is increasingly recognized as a clinical entity that can be treated with escalation of therapy in the ambulatory setting, possibly avoiding hospitalization. ${ }^{14}$ WHF is in fact now included as a clinical endpoint, separate from mortality or HF hospitalization, in clinical trials. ${ }^{16}$ Importantly, while hospitalization confers a significant increase in mortality, recent data suggest that ambulatory patients with WHF also suffer a poor prognosis. ${ }^{21-24}$ Thus, strategies for the prevention, detection and prompt treatment of WHF episodes can aid HF management in the outpatient setting. 
Table 1: Advantages and challenges of ambulatory management of worsening heart failure

\begin{tabular}{|l|l|}
\hline Advantages & Challenges \\
\hline Increased out-of-hospital days & Decreased vital sign and laboratory monitoring \\
\hline Increased patient empowerment over medical care & Limitations in available medications/routes of administration \\
\hline $\begin{array}{l}\text { Increased participation by caregivers/care partners } \\
\text { Decreased exposure to risks of hospitalization (i.e. infection, venous } \\
\text { thromboembolism, need for physical rehabilitation) }\end{array}$ & Potential delays in obtaining imaging/studies \\
\hline $\begin{array}{l}\text { Decreased acute care (emergency department, hospital) resource utilization } \\
\text { and cost }\end{array}$ & $\begin{array}{l}\text { Need for ambulatory infrastructure and resources to receive and interpret } \\
\text { tele- and remote-monitoring patient data }\end{array}$ \\
\hline
\end{tabular}

\section{Detection of worsening heart failure through patient monitoring \\ Self-care practices}

Effective monitoring of the patient's clinical status is central to timely outpatient HF care. The burden of daily evaluation for signs and symptoms of WHF falls largely on patients and caregivers. ${ }^{25}$ Symptom monitoring, in addition to adherence to medications and preventative behaviours (such as dietary fluid and sodium restriction), comprise the foundation of HF self-care maintenance. Patients who are able to engage in self-care management have better outcomes. Among 195 patients with $\mathrm{HF}$, Lee et al. demonstrated that patients with above average HF self-care management had a statistically significant $56 \%$ risk reduction in all-cause mortality, hospitalization or emergency room admission. ${ }^{26}$ Unfortunately, other studies have shown that HF self-care behaviours are performed infrequently and symptoms are often misinterpreted as unrelated to $\mathrm{HF}^{27,28}$

Adjuncts to patient self-care include structured telephone support and home visits, which are often employed after hospital discharge in efforts to prevent re-admission. ${ }^{29}$ Structured telephone calls provide opportunities for monitoring and education through regular contact. Home-visiting programmes allow clinicians to meet patients in their home environment and provide reinforcement of self-care practices, physical exams and medication reconciliation. These practices were recently evaluated in a meta-analysis of 47 randomized controlled trials, including 13 structured telephone support and 14 home-visiting programme studies. ${ }^{29}$ Home visits significantly reduced all-cause readmission (relative risk [RR] 0.75; 95\% confidence interval $[\mathrm{Cl}]$ 0.68-0.86, number needed to treat [NNT] 9) and HF-specific re-admission (RR 0.51; 95\% Cl 0.31-0.82; NNT 7) over 3-6 months. However, structured telephone support did not significantly reduce the risk of all-cause re-admission or HF-specific re-admission. These findings were demonstrated again in a more recent analysis by van spall and colleagues, who also found that home visits reduced healthcare costs compared with usual care. ${ }^{30}$

\section{Remote monitoring}

Remote monitoring involves the use of handheld, wearable or implantable devices to capture and transmit clinical data to a healthcare provider for purposes of monitoring and providing care, often in conjunction with telephone or video consultations." Through regular collection of physiologic data, clinicians may be able to identify early signs of decompensation and intervene before hospitalization becomes necessary. ${ }^{31}$ The past two decades have seen rapid advancements in HF telemonitoring devices, with many more on the horizon. ${ }^{32}$ One strategy incorporates implantable cardiac device-based diagnostics, such as intrathoracic impedance, heart rhythm and heart rate variability, to identify patients at high risk of hospitalization. ${ }^{33-35}$ In the MultiSENSE (Multisensor Chronic Evaluation in Ambulatory Heart Failure Patients) trial, the multisensor-based algorithm HeartLogic (Boston Scientific
Corporation, Marlborough, MA, USA) was developed and validated in a study of 900 patients. ${ }^{36}$ The algorithm was found to have sensitivity of $70 \%$ (95\% Cl 55.4-82.1\%) and alerted a median of 34 days prior to a HF event (interquartile range [IQR] 19.0-66.3 days).

Implantable wireless haemodynamic monitors are an alternative to device-based algorithms. One such device is the CardioMEMS HF System (CardioMEMS, Inc., Atlanta, GA, USA), a sensor that directly measures pulmonary arterial pressures and transmits data wirelessly. The prospective, single-blinde CHAMPION (CardioMEMS Heart Sensor Allows Monitoring of Pressure to Improve Outcomes in NYHA Class III Heart Failure Patients) trial randomized 550 patients to management with a wireless haemodynamic monitoring system, incorporating daily pulmonary artery pressure measurements (treatment) or control. ${ }^{37}$ Over 6 months, there was a $28 \%$ risk reduction in HF-related hospitalization in the treatment group (hazard ratio [HR] 0.72; 95\% $\mathrm{Cl} 0.60-0.85 ; \mathrm{p}=0.0002$ ). A post-hoc analysis of patients with left ventricular ejection fraction receiving HF guideline-directed medical therapy also demonstrated a $47 \%$ decrease in mortality ( $\mathrm{HR} 0.63 ; 95 \% \mathrm{Cl} 0.41-0.96 ; \mathrm{p}=0.0293){ }^{38} \mathrm{~A}$ recent meta-analysis of five trials of implantable wireless haemodynamic monitoring systems demonstrated similar results, finding a $38 \%$ reduction in HF events when compared with standard care (HR 0.62; $95 \% \mathrm{Cl}$ 0.50-0.78; $p<0.001){ }^{39}$ These data prompted the European Society of Cardiology 2016 HF guidelines to include the use of implantable pulmonary artery pressure monitoring in patients with a previous HF hospitalization as a class $\mathrm{lb}$ recommendation to reduce the risk of recurrent hospitalization..$^{40}$

Despite several studies failing to demonstrate benefit, meta-analyses have suggested that telemonitoring interventions can decrease HF hospitalizations and improve mortality. ${ }^{41-44} \mathrm{~A}$ more recent analysis of multiple systematic reviews by Kitsiou et al. further delineated the individual impact of four categories of telemonitoring interventions in an exploratory post-hoc analysis: automated device-based telemonitoring, mobile telemonitoring, interactive voice response systems, and video-conferencing with vital signs monitoring. ${ }^{31}$ Of these approaches, automated device-based telemonitoring demonstrated the most significant benefit, with a $35 \%$ reduction in all-cause mortality (RR $0.65 ; 95 \% \mathrm{Cl} 0.54-0.79 ; \mathrm{p}<0.001)$ and $23 \% \mathrm{RR}$ reduction in HF-related hospitalizations (RR $0.77 ; 95 \% \mathrm{Cl} 0.64-0.91 ; \mathrm{p}=0.003$ ). Interactive voice response systems, involving the manual input of data by the patient into a telephone keypad in response to automated voice prompts, were not shown to reduce mortality or hospitalizations. However, Kitsiou et al. note that prior analyses have evaluated multiple types of telemonitoring approaches as one standardized intervention, potentially obscuring the differences in efficacy of each approach. The lack of high-quality evidence to support or dispute the benefits of telemonitoring suggests that more data are needed to guide telemonitoring practice in $\mathrm{HF}^{31,45}$ 


\section{Ambulatory treatment of worsening heart failure} Identification of WHF requires prompt intervention to decrease congestion and circumvent hospitalization. Loop diuretics, such as furosemide, are a cornerstone in the treatment of both acute and chronic heart failure. Loop diuretics block sodium reabsorption in nephrons, facilitating natriuresis. ${ }^{46,47}$ Bioavailability varies by agent and administration route. ${ }^{47} \mathrm{In}$ WHF, diuretic absorption and effect can be reduced due to gut wall oedema or decreased abdominal blood flow. ${ }^{48}$ Bumetanide and torsemide (torasemide) both offer higher, more reliable oral absorption (80-100\% bioavailable) and may be options for patients who do not respond to oral furosemide. ${ }^{46,47}$ An alternative approach is the addition of a thiazide diuretic, such as metolazone. These drugs inhibit the compensatory sodium avidity seen in the distal nephron in response to loop diuretic use, thus augmenting natriuresis by a complementary mechanism. ${ }^{49}$ With guidance from the care team, patients may be able to titrate diuretics and trial these approaches at home to prevent WHF.

Despite these strategies, patients frequently require IV diuretics for decongestion. ${ }^{50}$ Historically, treatment with IV diuretics has necessitated inpatient admission; however, health systems are increasingly mobilizing ambulatory HF clinics to offer outpatient IV diuretic administration. These integrated disease management clinics, or same-day access clinics, are staffed with multidisciplinary teams, which may include physicians, advanced practice providers, nurses, pharmacists, dieticians and social workers." They are equipped to provide transitional care following hospital discharge, including diuretic titration, guideline-directed medical therapy optimization and HF education. Same-day access clinics can serve an invaluable role in the triage and treatment of WHF, including the administration of IV diuretics. The feasibility and safety of outpatient IV diuretics have been described in several single-centre studies. ${ }^{51-54}$ Additionally, outpatient IV diuretics may play a role in the management of specific at-risk HF populations, such as those with restrictive cardiomyopathy, with a recent study of ambulatory IV diuresis in patients with cardiac amyloidosis demonstrating a decrease in the number of acute care visits and hospital days. ${ }^{55}$ An alternative strategy to IV outpatient diuresis on an as-needed basis may be the use of intermittent empirical diuretics, which could also be facilitated through an HF clinic and has shown potential benefit in case reports. ${ }^{56}$

While the outpatient administration of IV diuretics offers a potentially effective, cost-saving route for the treatment of WHF, this strategy is not without barriers. ${ }^{53,57}$ Patients are still required to come to the clinic, which may be challenging for symptomatic or immobile patients, or those living in remote areas. Additionally, not all outpatient clinics are equipped to accommodate IV diuretic administration. Medication administration requires placement of an IV line by a skilled nurse or technician, and may be associated with complications such as infection and thrombosis (though rare). ${ }^{10}$

\section{Future directions}

\section{Role of telemedicine and patient monitoring}

As noted above, patients with HF may have several barriers to in-person care, and worsening symptoms that might otherwise be managed in the clinic may instead result in calls to emergency medical services. The recent worldwide COVID-19 pandemic has additionally necessitated changes across healthcare systems, drastically reducing ambulatory clinic capacity in favour of virtual visits. ${ }^{58}$ The effects of social isolation, physical inactivity, emotional stress and dietary changes during the pandemic on patients with HF have been further compounded by patients' hesitation to seek care and risk exposure. ${ }^{59-61}$ Recognizing the potential role for telemedicine in the care of patients with $\mathrm{HF}$, the Heart
Failure Society of America recently issued an expert consensus statement on the use of telehealth in $\mathrm{HF}^{58}$ These guidelines, in conjunction with widespread amendments to telehealth-related reimbursement policies across major insurance carriers, have fuelled an interest in developing effective practices for telehealth. Potential benefits include expanding access to timely clinical care, allowing increased caregiver involvement, facilitating clinician interaction with the patient's home environment and, currently key, reducing potential exposures to COVID-19. However, challenges remain, including limitations in patients' ability to check vital signs and weight, the inability to perform a comprehensive physical exam, technical difficulties with video conferencing and disparities in access to technology. Furthermore, patients evaluated via a virtual visit may still require in-person assessment or treatment.

Early experience with transitioning to a telemedicine-based strategy has highlighted the importance of empowering patients to use self-management strategies and remote monitoring to enhance virtual visits. ${ }^{62}$ For example, the early months of the pandemic brought a notable increase in the use of CardioMEMS in Europe, the Middle East and Africa, associated with a decrease in HF hospitalizations. ${ }^{63}$ Centres in the USA have also reported a reduction in HF hospitalizations among patients monitored by implantable haemodynamic monitoring devices during this period, as well as an increase in clinician-patient interactions related to HF management. ${ }^{64,65}$ Importantly, it is imperative to retain in-person access to clinics for the purpose of triage and treatment of acutely decompensated patients. ${ }^{62}$

\section{At-home treatment of worsening heart failure}

With notable advancements in remote monitoring and management, the next frontier in HF care is at-home treatment of WHF. Subcutaneous (SC) injections of furosemide present an effective alternative to IV formulations.6-68 Previously, the SC use of commercially available furosemide formulations was impeded by their high alkaline $\mathrm{pH}$, which caused irritation at the injection site. ${ }^{61}$ The development of a novel, buffered furosemide formulation (scFurosemide; scPharmaceuticals, Inc., Burlington, MA, USA) with a pH of 7.4 helped to alleviate injection site complications. ${ }^{68}$ Initial studies of this agent, delivered in a biphasic dosing profile via an external infusion pump (30 mg over 60 minutes followed by $12.5 \mathrm{mg} / \mathrm{h}$ for 4 hours), demonstrated that it was well-tolerated and effective when compared with the IV formulation. ${ }^{68}$ Therapeutic furosemide levels were observed as early as 30 minutes after SC infusion initiation and resulted in diuresis and natriuresis similar to that produced by the IV route. ${ }^{68}$

These studies were followed by a randomized, phase II trial of 41 patients presenting to an ambulatory HF clinic with WHF. ${ }^{69}$ In the first 6-hour interval after drug administration, patients in the IV and SC groups had similar median urine output (IV 1,325 mL [IQR 1,075-1,350 mL]; SC 1,350 mL [IQR 900-1,900 mL]) and weight loss (IV -1.5 $\pm 1.1 \mathrm{~kg}$; $\mathrm{SC}-1.5 \pm 1.2 \mathrm{~kg})$. One patient in the SC group experienced mild hypokalaemia; no other adverse events were reported. SC furosemide formulations have also been shown to be of value for patients with HF in palliative settings. ${ }^{70,71}$

As experience with outpatient use of SC furosemide increases, there is interest in ultimately gaining approval for an SC formulation that can be administered at home. ${ }^{72}$ Several studies are ongoing or planned in the near-term to assess the safety and efficacy of wearable furosemide drug-delivery systems. ${ }^{73-75}$ For example, FUROSCIX ${ }^{\circledR}$ (SCPharmaceuticals, Inc., Burlington, MA, USA) is pre-programmed to deliver $80 \mathrm{mg}$ of SC furosemide to the patient through an adhesive pump. Patients presenting with WHF both to ambulatory and acute care settings will be treated with 


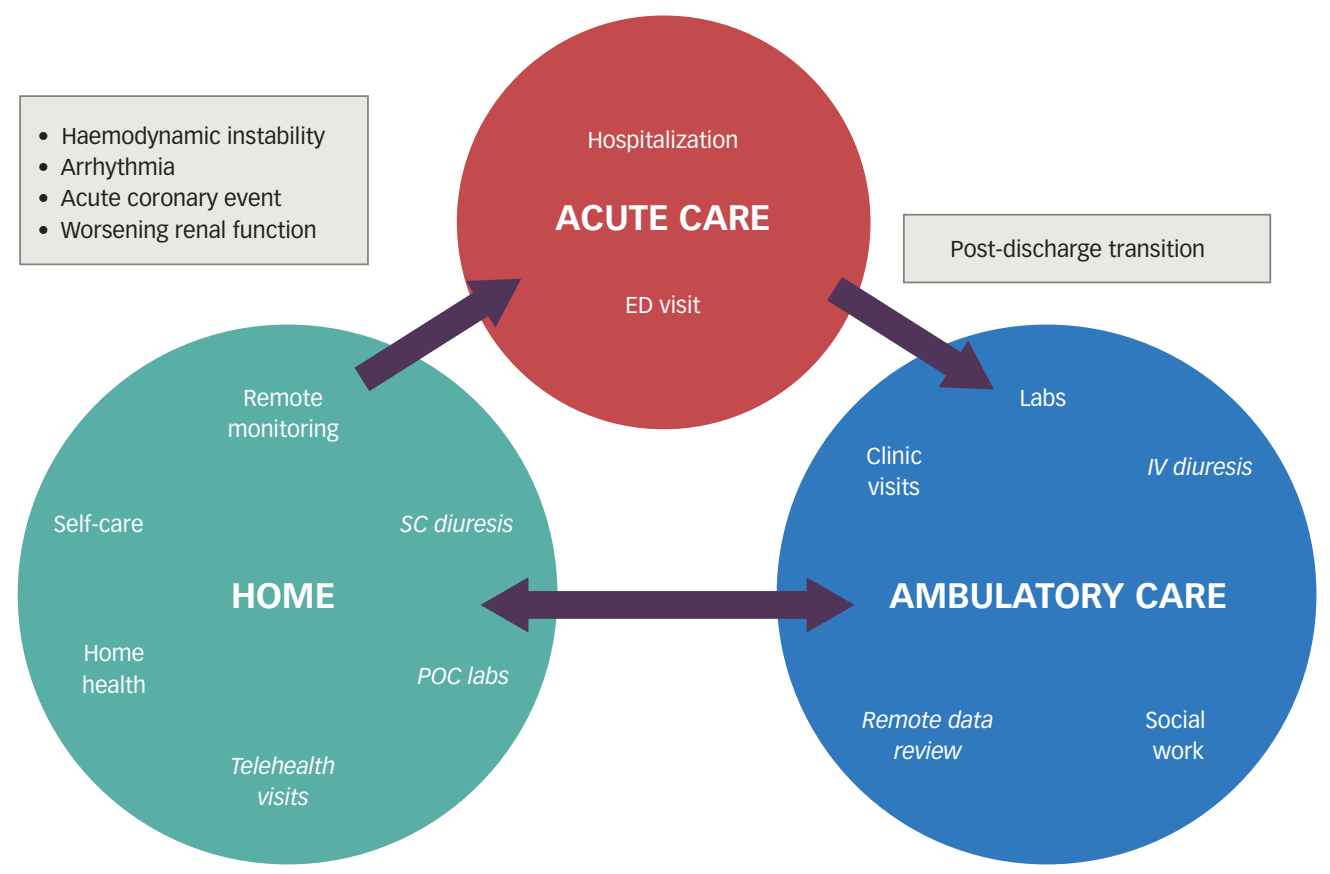

Italicised items represent opportunities for future growth.

$E D=$ emergency department; $I V=$ intravenous; $P O C=$ point of care; $S C=$ subcutaneous.

these SC furosemide formulations, with outcomes including cost of care, hospitalization, and patient-reported outcomes, such as quality of life.

With the use of remote monitoring and televisits to adjust medical therapies and the potential for more potent at-home diuresis, naturally point-of-care mechanisms to monitor electrolytes, such as potassium, are needed. The i-STAT (Abbott Laboratories, Chicago, IL, USA) is one such device that has been investigated for use in home visits. ${ }^{76}$ One could imagine a future workflow that includes the remote incorporation of haemodynamic data, symptoms and laboratories, which then prompts a clinician-initiated 'prescription' for WHF that may be available for pick up or delivery to a patient's home (Figure 1).

Lastly, in those patients who develop diuretic resistance, for example in the setting of progressive renal dysfunction requiring renal replacement therapy, peritoneal dialysis may be considered as an option that allows patients to remain at home. Several small observational studies have shown that peritoneal dialysis may have a role in the treatment of WHF in patients with end-stage or diuretic-refractory HF with or without end-stage renal disease, decreasing hospitalizations and improving New York Heart Association class..$^{77.78}$ Peritoneal dialysis may offer ultrafiltration that can relieve congestion without significant fluid shifts, and, importantly, can be managed at home by motivated patients and caregivers.

\section{Conclusion}

Heart failure is an increasing health and economic challenge in the USA. Alleviating the toll on patients and their caregivers, as well as decreasing the cost burden on the healthcare system, depends significantly on the ability to transition care from the hospital to the outpatient clinic or, increasingly, to home. Multiple recent innovations in HF management may work to streamline treatment in the ambulatory or home setting and help to provide effective, cost-saving, patient-centred care for patients with HF. $\square$
1. Yancy CW, Jessup M, Bozkurt B, et al. 2013 ACCF/AHA guideline for the management of heart failure: $A$ report of the American College of Cardiology Foundation/American Heart Association Task Force on practice guidelines. J Am Coll Cardiol. 2013;62:e147-239.

2. Virani SS, Alonso A, Benjamin EJ, et al. Heart disease and stroke statistics-2020 update: A report from the American Heart Association. Circulation. 2020;141:E139-596.

3. Heidenreich PA, Albert NM, Allen LA, et al. Forecasting the impact of heart failure in the United States. Circ Heart Fail. 2013;6:606-19.

4. MCMurray JJV, Solomon SD, Inzucchi SE, et al. Dapagliflozin in patients with heart failure and reduced ejection fraction. N Eng J Med. 2019;381:1995-2008.

5. McMurray JJV, Packer M, Desai AS, et al. Angiotensin-neprilysin inhibition versus enalapril in heart failure. N Eng/ J Med. 2014;371:993-1004.

6. Dunlay SM, Roger VL. Understanding the epidemic of heart failure: past, present, and future. Curr Heart Fail Rep. 2014;11:404-15.

7. Lesman-Leegte I, Jaarsma T, Coyne JC, et al. Quality of life and depressive symptoms in the elderly: a comparison between patients with heart failure and age- and gender-matched community controls. I Card Fail. 2009:15:17-23.

8. Bidwell JT, Lyons KS, Lee CS. Caregiver well-being and patient outcomes in heart failure. J Cardiovasc Nurs. 2017;32:372-382. Go AS, Mozaffarian D, Roger VL, et al. Heart disease and stroke statistics-2013 update: A Report from the American Heart Association. Circulation. 2013;127.e6-e245.

10. Afari ME, Aoun J, Khare S, Tsao L. Subcutaneous furosemide for the treatment of heart failure: a state-of-the art review. Heart Fail Rev. 2019:24:309-13.

11. Zsilinszka R, Mentz RJ, DeVore AD, et al. Acute heart failure: alternatives to hospitalization. JACC Heart Fail. 2017:5:329-36.

12. Fitch K, Lau J, Engel T, et al. The cost impact to Medicare of shifting treatment of worsening heart failure from inpatient to outpatient management settings. Clinicoecon Outcomes Res. 2018;10:855-63.

13. Matsue $Y$, Damman $K$, Voors AA, et al. Time-to-furosemide treatment and mortality in patients hospitalized with acute heart failure. J Am Coll Cardiol. 2017;69:3042-51.

14. Greene SJ, Mentz RJ, Felker GM. Outpatient worsening heart failure as a target for therapy. JAMA Cardiol. 2018;3:252-9.

15. Weatherley BD, Milo-Cotter O, Michael Felker G, et al. Early worsening heart failure in patients admitted with acute heart failure - a new outcome measure associated with long-term prognosis? Fundam Clin Pharmacol. 2009;23:633-9.

16. Cooper LB, DeVore AD, Michael Felker G. The impact of worsening heart failure in the United States. Heart Fail Clin. 2015:11:603-14.
17. Gheorghiade M, Filippatos G, De Luca L, Burnett J. Congestion in acute heart failure syndromes: an essential target of evaluation and treatment. Am J Med. 2006;119(Suppl.1):S3-10.

18. Drazner MH, Stevenson LW. Relief and prevention of congestion in heart failure enhance quality and length of life. Circulation. 2019;140:1380-2.

19. Yancy CW, Lopatin M, Stevenson LW, et al. Clinical presentation, management, and in-hospital outcomes of patients admitted with acute decompensated heart failure with preserved systolic function: A report from the Acute Decompensated systolic function: A report from the Acute Decompensated
Heart Failure National Registry (ADHERE) database. J Am Coll Cardiol. 2006:47:76-84.

20. Ambrosy AP, Fonarow GC, Butler J, et al. The global health and economic burden of hospitalizations for heart failure: Lesson learned from hospitalized heart failure registries. J Am Coll Cardiol. 2014;63:1123-33.

21. Solomon SD, Dobson J, Pocock S, et al. Influence of nonfatal hospitalization for heart failure on subsequent mortality in patients with chronic heart failure. Circulation. 2007;116:1482-7.

22. Okumura N, Jhund PS, Gong J, et al. Importance of clinical worsening of heart failure treated in the outpationt settin : worsening of heart fallure treated in the outpatient setting: evidence from the Prospective Comparison of ARNI With ACEI to Determine Impact on Global Mortality and Morbidity in He 
23. Madelaire C, Gustafsson F, Stevenson LW, et al. One-year mortality after intensification of outpatient diuretic therapy. J Am Heart Assoc. 2020;9:e016010.

24. Skali H, Dwyer EM, Goldstein R, et al. Prognosis and response to therapy of first inpatient and outpatient heart failure event in a heart failure clinical trial: MADIT-CRT. Eur J Heart Fail. 2014;16:560-5.

25. Riegel B, Moser DK, Anker SD, et al. State of the science Circulation. 2009;120:1141-63.

26. Lee CS, Moser DK, Lennie TA, Riegel B. Event-free survival in adults with heart failure who engage in self-care management Heart Lung. 2011;40:12-20.

27. Artinian NT, Magnan M, Sloan M, Lange MP. Self-care behaviors among patients with heart failure. Heart Lung. 2002;31:161-72.

28. Carlson B, Riegel B, Moser DK. Self-care abilities of patients with heart failure. Heart Lung. 2001;30:351-9.

29. Feltner $C$, Jones $C D$, Cené $C W$, et al. Transitional care interventions to prevent readmissions for persons with heart failure: A systematic review and meta-analysis. Ann Intern Med. 2014;160:774-84.

30. Van Spall HGC, Rahman T, Mytton O, et al. Comparative effectiveness of transitional care services in patients discharged from the hospital with heart failure: A systematic review and network meta-analysis. Eur J Heart Fail. 2017; 19:1427-43.

31. Kitsiou S, Paré G, Jaana M. Effects of home telemonitoring interventions on patients with chronic heart failure: An overview of systematic reviews. J Med Internet Res. 2015;17:e63.

32. Bekfani T, Fudim M, Cleland JGF, et al. A current and future outlook on upcoming technologies in remote monitoring of patients with heart failure Eur I Heart Fail. 2021:23:175-85.

33. Perego $G B$, Landolina $M$, Vergara $G$, et al. Implantable CRT device diagnostics identify patients with increased risk for device diagnostics identify patients with increased risk for heart failure hospit

34. Cowie MR, Sarkar S, Koehler J, et al. Development and validation of an integrated diagnostic algorithm derived from parameters monitored in implantable devices for identifying patients at risk for heart failure hospitalization in an ambulatory setting. Eur Heart J. 2013;34:2472-80.

35. Gula $\sqcup$, Wells GA, Yee R, et al. A novel algorithm to assess risk of heart failure exacerbation using ICD diagnostics: Validation from RAFT. Heart Rhythm. 2014;11:1626-31.

36. Boehmer JP, Hariharan R, Devecchi FG, et al. A multisensor algorithm predicts heart failure events in patients with implanted devices: Results from the MultiSENSE Study. JACC Heart Fail. 2017:5:216-25.

37. Abraham WT, Adamson PB, Bourge RC, et al. Wireless pulmonary artery haemodynamic monitoring in chronic hulmonary artery haemodynamic monitoring in chro 2011;377:658-66.

38. Givertz MM, Stevenson LW, Costanzo MR, et al. Pulmonary artery pressure-guided management of patients with hear failure and reduced ejection fraction. I Am Coll Cardiol. 2017;70:1875-86.

39. Adamson PB, Ginn G, Anker SD, et al. Remote haemodynamic-guided care for patients with chronic heart failure: a meta-analysis of completed trials. Eur J Heart Fail. 2017;19:426-33.

40. Ponikowski P, Voors AA, Anker SD, et al. 2016 ESC Guidelines for the diagnosis and treatment of acute and chronic heart failure: The Task Force for the diagnosis and treatment of acute and chronic heart failure of the European Society of acute and chS the Heart Failure Association (HFA) of the ESC. Eur Heart J. 2016;37:2129-200.

41. Ong MK, Romano PS, Edgington S, et al. Effectiveness of remote patient monitoring after discharge of hospitalized patients with heart failure: The Better Effectiveness After Transition - Heart
Failure (BEAT-HF) randomized clinical trial. JAMA Intern Med. 2016;176:310-8.

42. Koehler F, Winkler S, Schieber M, et al. Impact of remote telemedical management on mortality and hospitalizations in ambulatory patients with chronic heart failure: The telemedica interventional monitoring in heart failure study. Circulation. 2011;123:1873-80

43. Clark RA, Inglis SC, MCAlister FA, et al. Telemonitoring or structured telephone support programmes for patients with chronic heart failure: Systematic review and meta-analysis. BMJ. 2007;334:942

44. Klersy C, De Silvestri A, Gabutti G, et al. A meta-analysis of remote monitoring of heart failure patients. J Am Coll Cardiol. 2009;54:1683-94

45. Maric B, Kaan A, Ignaszewski A, Lear SA. A systematic review of telemonitoring technologies in heart failure. Eur $\mathrm{J}$ Heart Fail. 2009;11:506-17.

46. Ellison DH, Felker GM. Diuretic treatment in heart failure. N Engl J Med. 2017;377:1964-75.

47. Shankar SS, Brater DC. Loop diuretics: From the Na-K-2C transporter to clinical use. Am J Physiol Renal Physiol. transporter to clin

48. Vargo DL, Kramer WG, Black PK, et al. Bioavailability, pharmacokinetics, and pharmacodynamics of torsemide and furosemide in patients with congestive heart failure Clin Pharmacol Ther. 1995;57:601-9.

49. Rao VS, Planavsky N, Hanberg JS, et al. Compensatory distal reabsorption drives diuretic resistance in human heart failure. J Am Soc Nephrol. 2017;28:3414-24.

50. Peacock WF, Costanzo MR, De Marco T, et al. Impact of intravenous loop diuretics on outcomes of patients hospitalized with acute decompensated heart failure: Insights from the ADHERE Registry. Cardiology. 2009;113:12-19.

51. Hebert K, Dias A, Franco E, et al. Open access to an outpatient intravenous diuresis program in a systolic heart failure disease management program. Congest Heart Fail. 2011;17:309-13.

52. Lazkani M, Ota KS. The role of outpatient intravenous diuretic therapy in a transitional care program for patients with heart failure: A case series. J Clin Med Res. 2012;4:434-8.

53. Al-Ani MA, Schwartz C, Winchester D, et al. Outpatien intravenous diuretic therapy for acute heart failure: A simplified solution to a formidable problem. J Card Fail. 2020;26:800-1.

54. Buckley LF, Carter DM, Matta L, et al. Intravenous diuretic therapy for the management of heart failure and volume overload in a multidisciplinary outpatient unit. JACC Heart Fail. 2016;4:1-8.

55. Vaishnav J, Hubbard A, Chasler JE, et al. Management of heart failure in cardiac amyloidosis using an ambulatory diuresis failure in cardiac amyloidosis using
clinic. Am Heart J. 2021:233:122-31.

56. Yetkin E, Cuglan B, Turhan $\mathrm{H}$, Ozturk S. A novel strategy to reduce the readmission rates in congestive heart failure: Intermittent empirical intravenous diuretics Cardiovasc Endocrinol Metab. 2020;9:60-3.

57. Buckley LF, Seoane-Vazquez E, Cheng JWM, et al. Comparison of ambulatory, high-dose, intravenous diuretic therapy to standard hospitalization and diuretic therapy for treatment of acute decompensated heart failure. Am J Cardiol. 2016;118:1350-5.

58. Gorodeski EZ, Goyal P, Cox ZL, et al. Virtual visits for care of patients with heart failure in the era of COVID-19: A statement from the Heart Failure Society of America. I Card Fail. 2020;26:448-56.

59. De Filippis EM, Reza N, Donald E, et al. Considerations for hear failure care during the COVID-19 pandemic. JACC Heart Fail. 2020;8:681-91.

60. Reza N, DeFilippis EM, Jessup M. Secondary impact of the COVID-19 pandemic on patients with heart failure Circ Heart Fail. 2020;13:e007219.

61. Toner L, Koshy AN, KO J, et al. Clinical characteristics and trends in heart failure hospitalizations. JACC Heart Fail. 2020;8:872-5.

62. Umapathi P, Cuomo K, Riley S, et al. Transforming ambulatory heart failure care in the coronavirus disease-19 era: Initial experience from a heart failure disease management clinic. J Card Fail. 2020;26:637-8.

63. Bayes-Genis A, Codina P, Abdul-Jawad Altisent O, et al. Advanced remote care for heart failure in times of COVID-19 using an implantable pulmonary artery pressure sensor: The new normal. Eur Heart J Suppl. 2020;22(Suppl. Pt):P29-32.

64. Almufleh A, Ahluwalia M, Givertz MM, et al. Short-term outcomes in ambulatory heart failure during the COVID-19 pandemic: Insights from pulmonary artery pressure monitoring. J Card Fail. 2020;26:633-4.

65. Oliveros E, Mahmood K, Mitter S, et al. Pulmonary artery pressure monitoring during the COVID-19 pandemic in New York City. J Card Fail. 2020:26:900-1.

66. Verma AK, da Silva JH, Kuhl DR. Diuretic effects of subcutaneous furosemide in human volunteers: A randomized pilot study. Ann Pharmacother. 2004;38:544-9.

67. Goenaga MA, Millet M, Sánchez E, et al. Subcutaneous furosemide. Ann Pharmacother. 2004;38:1751.

68. Sica DA, Muntendam P, Myers RL, et al. Subcutaneous furosemide in heart failure: Pharmacokinetic characteristics of a newly buffered solution. JACC Basic Trans/ SCi. 2018;3:25-34.

69. Gilotra NA, Princewill O, Marino B, et al. Efficacy of intravenous furosemide versus a novel, $\mathrm{pH}$-neutral furosemide formulation administered subcutaneously in outpatients with worsening heart failure. JACC Heart Fail. 2018;6:65-70.

70. Zacharias H, Raw J, Nunn A, et al. Is there a role for subcutaneous furosemide in the community and hospice management of end-stage heart failure? Palliat Med. 2011;25:658-63.

71. Farless $L B$, Steil $N$, Williams BR, Bailey FA. Intermittent subcutaneous furosemide: Parenteral diuretic rescue for hospice patients with congestive heart failure resistant to ora diuretic. Am J Hosp Palliat Care. 2013:30:791-2.

72. Zatarain-Nicolás E, López-Díaz J, de la Fuente-Galán L, et al. Subcutaneous infusion of furosemide administered by elastomeric pumps for decompensated heart failure treatmen Initial experience. Rev Esp Cardiol (Engl Ed). 2013;66:1002-4.

73. ClinicalTrials.gov. Furoscix real-world evaluation for decreasing hospital admissions in heart failure (FREEDOM-HF). ClinicalTrials.gov Identifier: NCT03458325. Available at: www.clinicaltrials.gov/ct2/show/NCT03458325 (accessed 18 January 2021).

74. ClinicalTrials.gov. Avoiding treatment in the hospital with Furoscix for the management of congestion in heart failure - A pilot study. ClinicalTrials. gov Identifier: NCT04593823. Available at: www.clinicaltrials.gov/ct2/show/NCT04593823 (accessed 18 February 2021).

75. Clinicaltrials.gov. Crossover study to compare the pharmacokinetics and bioavailability of a novel furosemide regimen administered subcutaneously vs. the same dose administered intravenously in subjects with chronic heart failure. ClinicalTrials.gov Identifier: NCT04384653. Available at: www.clinicaltrials.gov/ct2/show/NCT04384653 (accessed 18 January 2021).

76. Hayward G, Dixon S, Garland S, et al. Point-of-care blood tests during home visits by out-of-hours primary care clinicians; a mixed methods evaluation of a service improvement. BMJ Open. 2020;10:e033428.

77. Courivaud C, Kazory A, Crépin T, et al. Peritoneal dialysis reduces the number of hospitalization days in heart failure patients refractory to diuretics. Perit Dial Int. 2014;34:100-8.

78. Grossekettler L, Schmack B, Meyer K, et al. Peritoneal dialysis as therapeutic option in heart failure patients. ESC Heart Fail. 2019;6:271-9. 